\title{
Statistics In Brief: Minimum Clinically Important Difference- Availability of Reliable Estimates
}

\author{
Mitchell Maltenfort PhD, Claudio Díaz-Ledezma MD
}

Received: 6 October 2016/Accepted: 6 December 2016/Published online: 3 January 2017

(C) The Association of Bone and Joint Surgeons (B) 2016

\section{Background}

To enter the era of value-based orthopaedics ("health outcomes per dollar spent") [2, 19], clinical researchers will have to prove that each treatment produces a meaningful clinical improvement using outcomes that are relevant for patients. The American Association of Hip and Knee Surgeons has recommended the use of patient-reported outcome measures to evaluate the results of knee and hip arthroplasties [16]. Studies have focused on statistically detectable (sometimes called statistically significant) differences [35]; however, it can be possible to detect statistical differences between interventions that are so small as not to be discernible to patients. Such small differences may not justify the cost or risk of the intervention. It seems much more important that treatments

Each author certifies that he, or a member of his immediate family, has no funding or commercial associations (eg, consultancies, stock ownership, equity interest, patent/licensing arrangements, etc) that might pose a conflict of interest in connection with the submitted article.

All ICMJE Conflict of Interest Forms for authors and Clinical Orthopaedics and Related Research ${ }^{\mathbb{R}}$ editors and board members are on file with the publication and can be viewed on request. Each author certifies that his or her institution approved the human protocol for this investigation and that all investigations were conducted in conformity with ethical principles of research. This work was performed at The Rothman Institute at Thomas Jefferson University, Philadelphia, PA, USA.

M. Maltenfort ( $\square)$

The Rothman Institute at Thomas Jefferson University, 125 South 9th Street, Suite 1000, Philadelphia, PA 19106, USA

e-mail: mitchell.maltenfort@ rothmaninstitute.com

C. Díaz-Ledezma

Hospital Naval de Talcahuano, Talcahuano, Chile should result in clinical improvements big enough for patients to consider clinically important.

For a given outcome measure, we questioned how much improvement is needed for patients to consider the difference clinically important? Stated otherwise, what is the minimum clinically important differences (MCID) for a specific outcomes measurement tool, such as the SF-36 or the Oswestry Disability Index?

\section{Discussion}

According to Cook [5], the idea of the MCID was originally conceived by Jaeschke in 1989, whose definition was "the smallest difference in score in the domain of interest which patients perceive as beneficial and which would mandate, in the absence of troublesome side effects and excessive cost, a change in the patient management." Cook's interpretation of this seminal definition establishes two essential characteristics: (1) a minimal amount of change perceived by the patient; and (2) a change sufficiently relevant to determine a modification in patient management. The alternative term, minimal clinically important improvement (MCII) is defined as the "smallest change in measurement that signifies an important improvement" [16], and has encountered more support than the MCID in musculoskeletal research, especially in rheumatology [31, 32]. In the accompanying tables (Tables 1-8), we refer to their results as MCID or MCII, but acknowledge it may not be consistent among them. For simplicity, we will use the term MCID throughout this paper.

The application of MCIDs in clinical research has been difficult largely owing to various methods for estimating them [5, 14, 15]. Wright et al. [35] enumerates nine possible methods that can be divided in two possible 


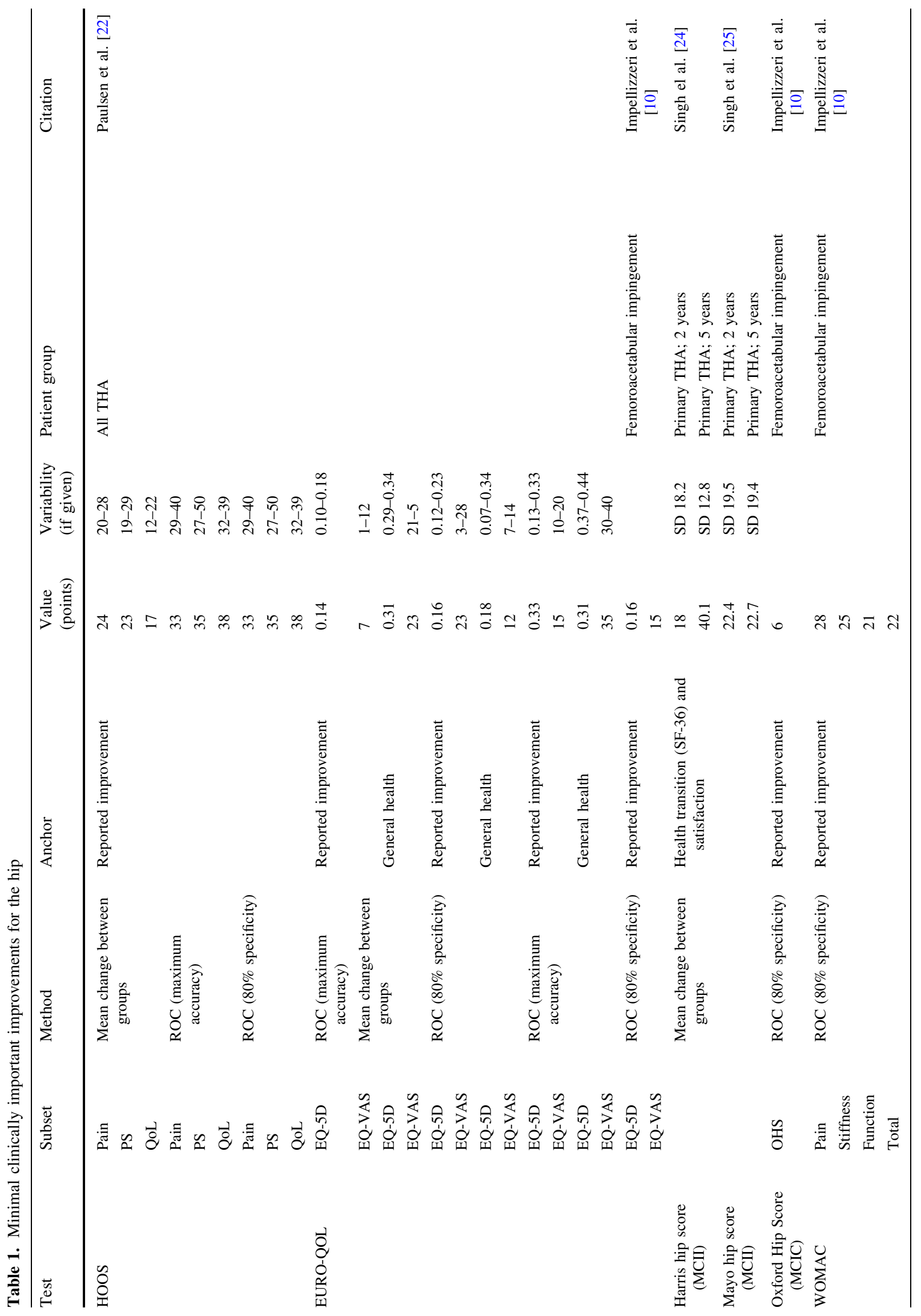




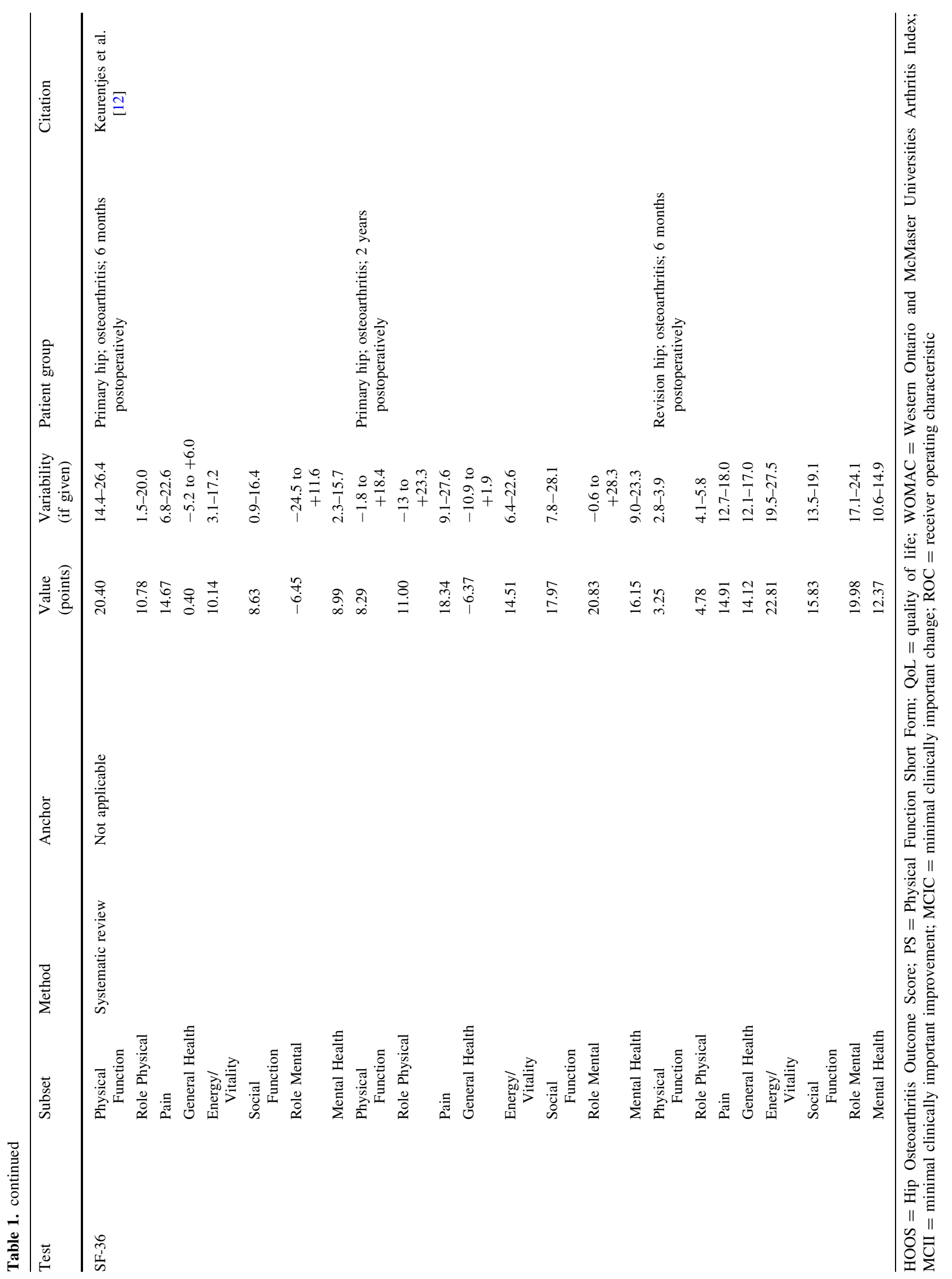




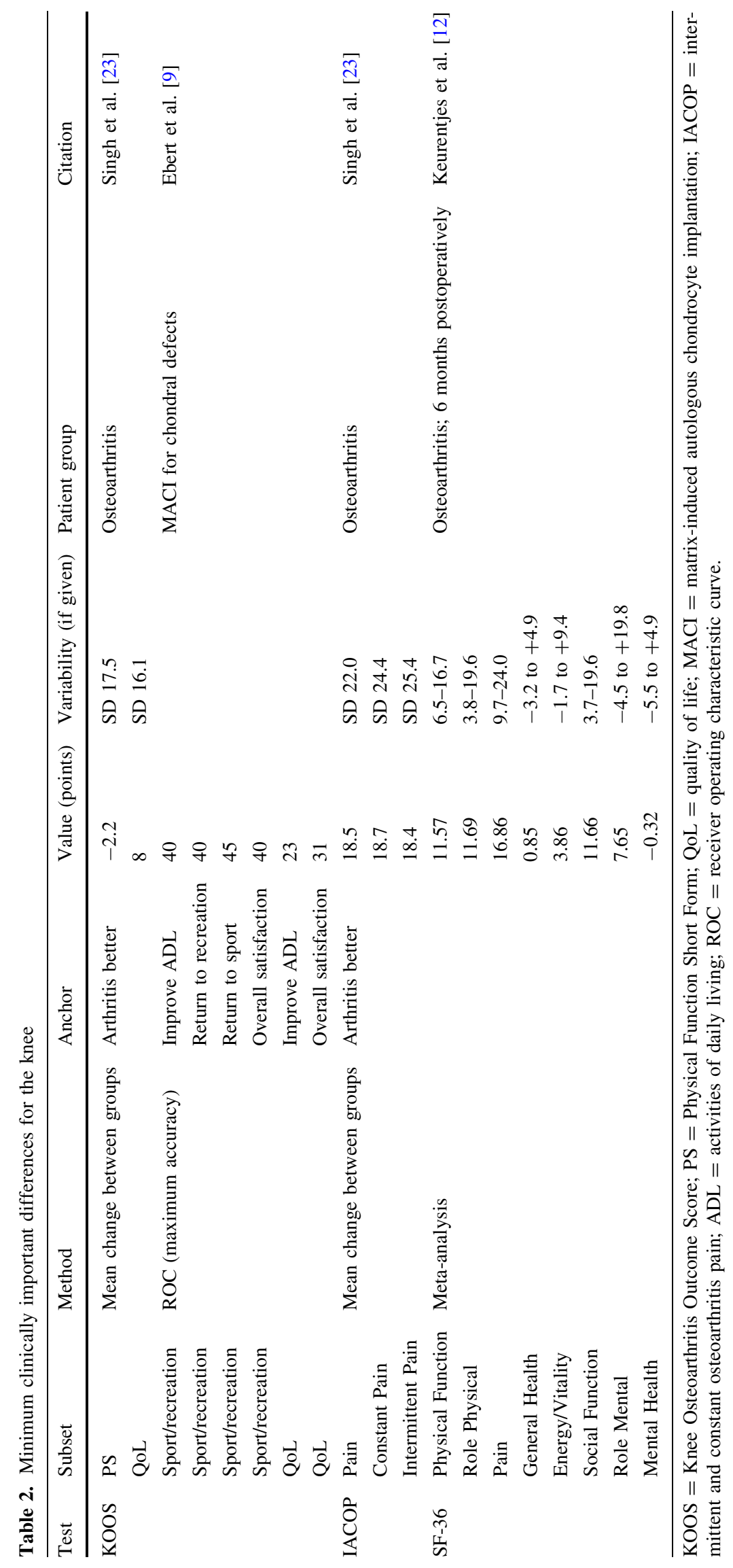




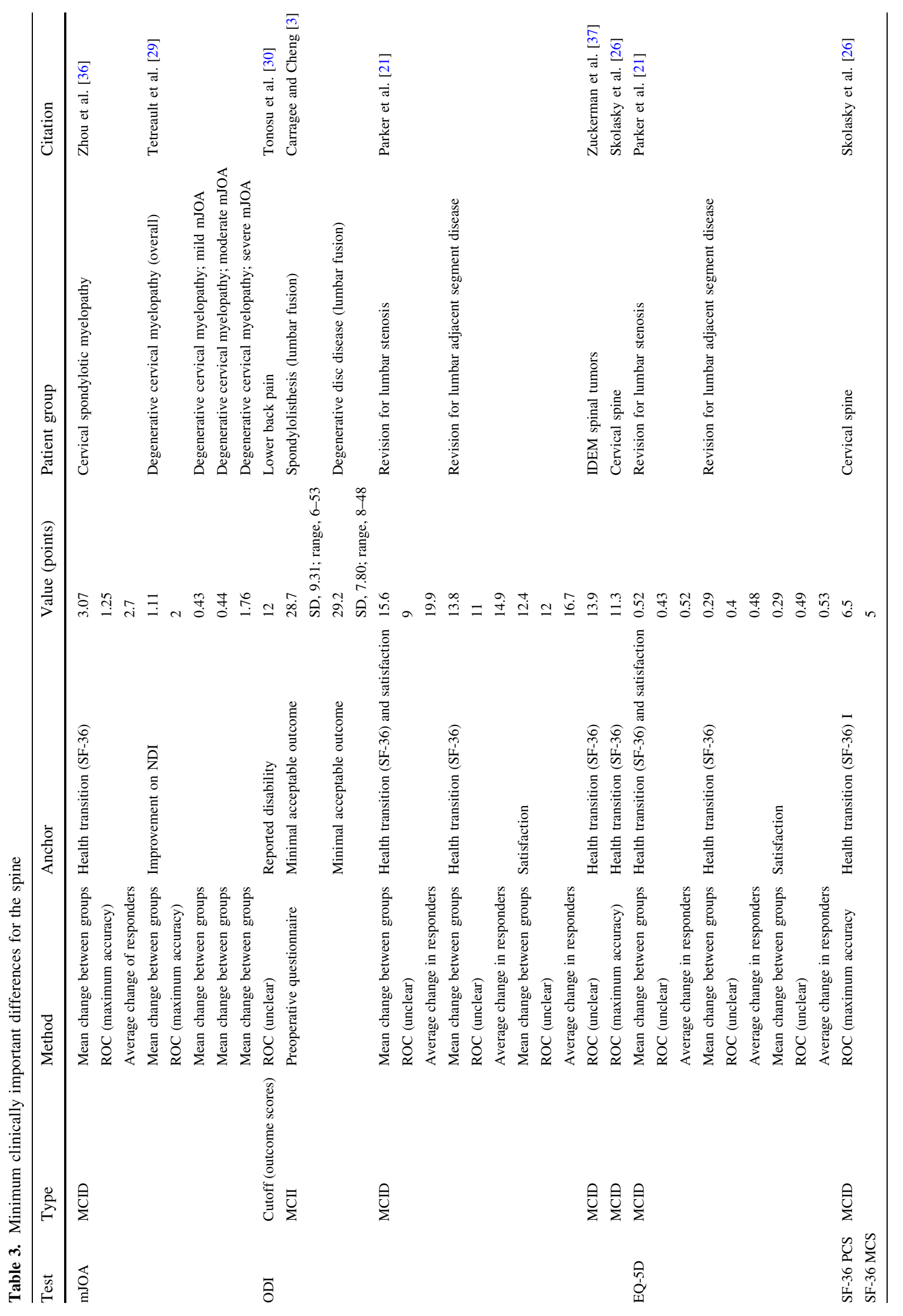




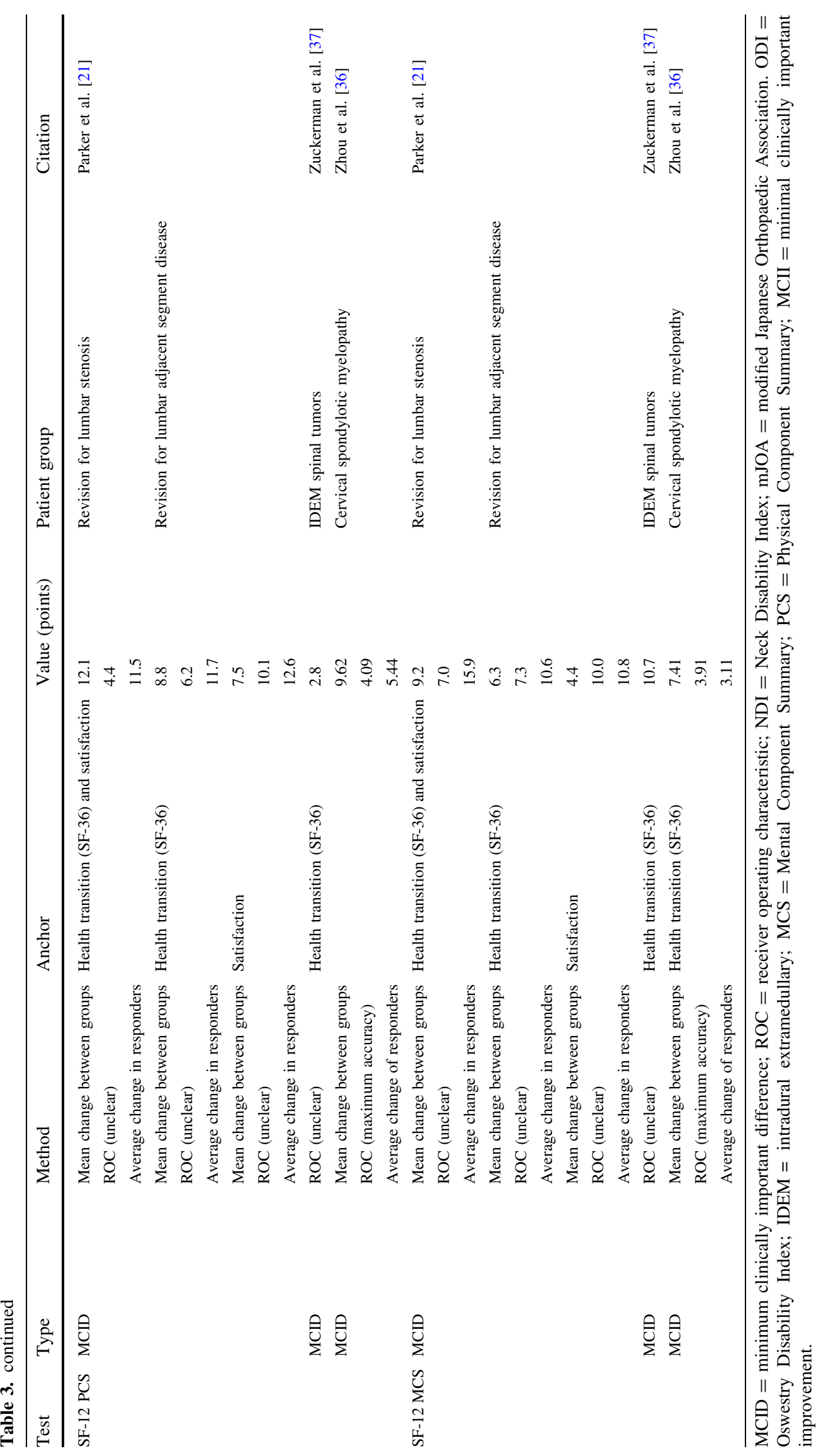




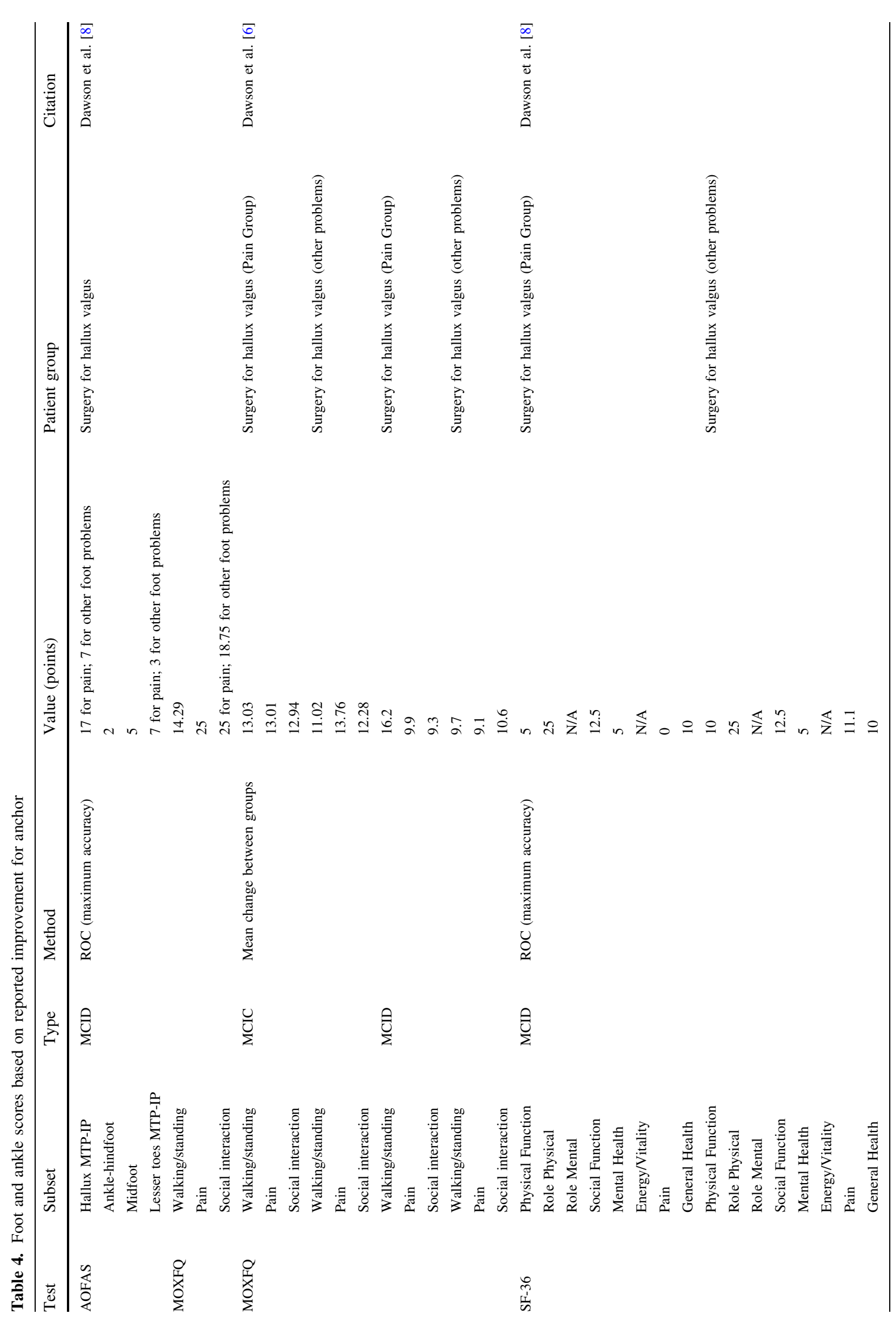




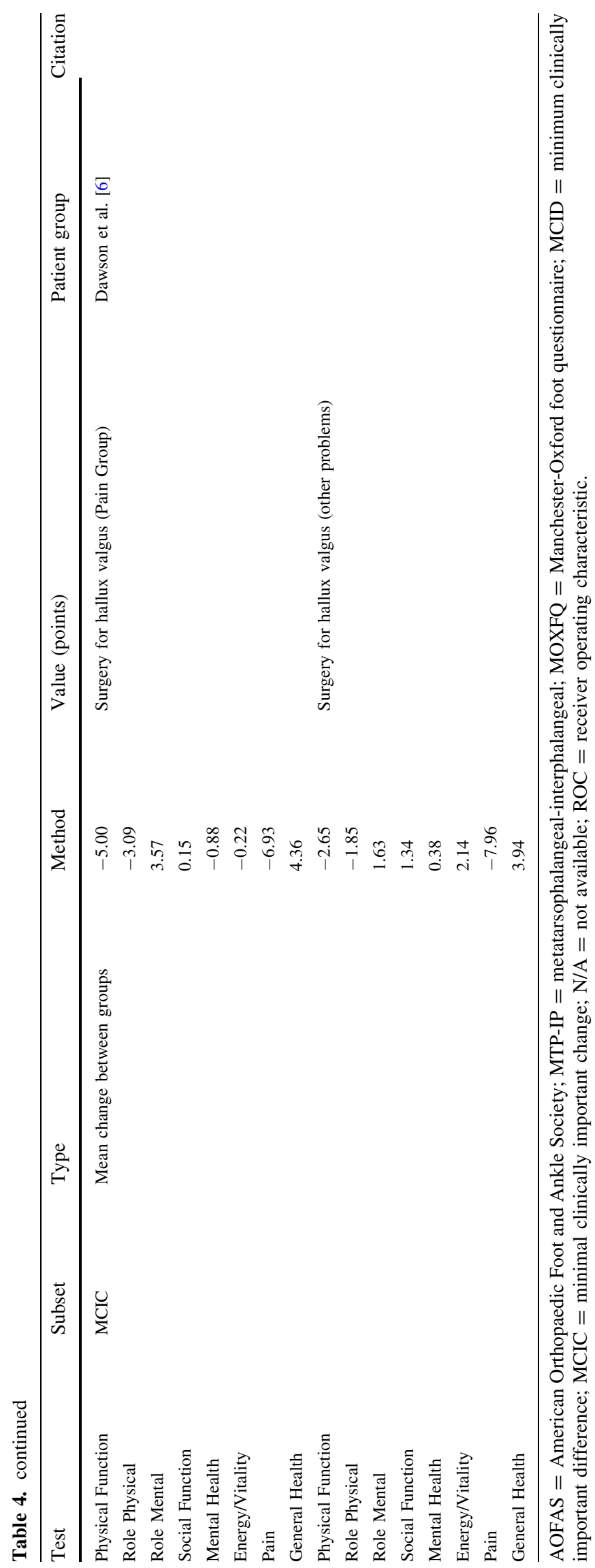




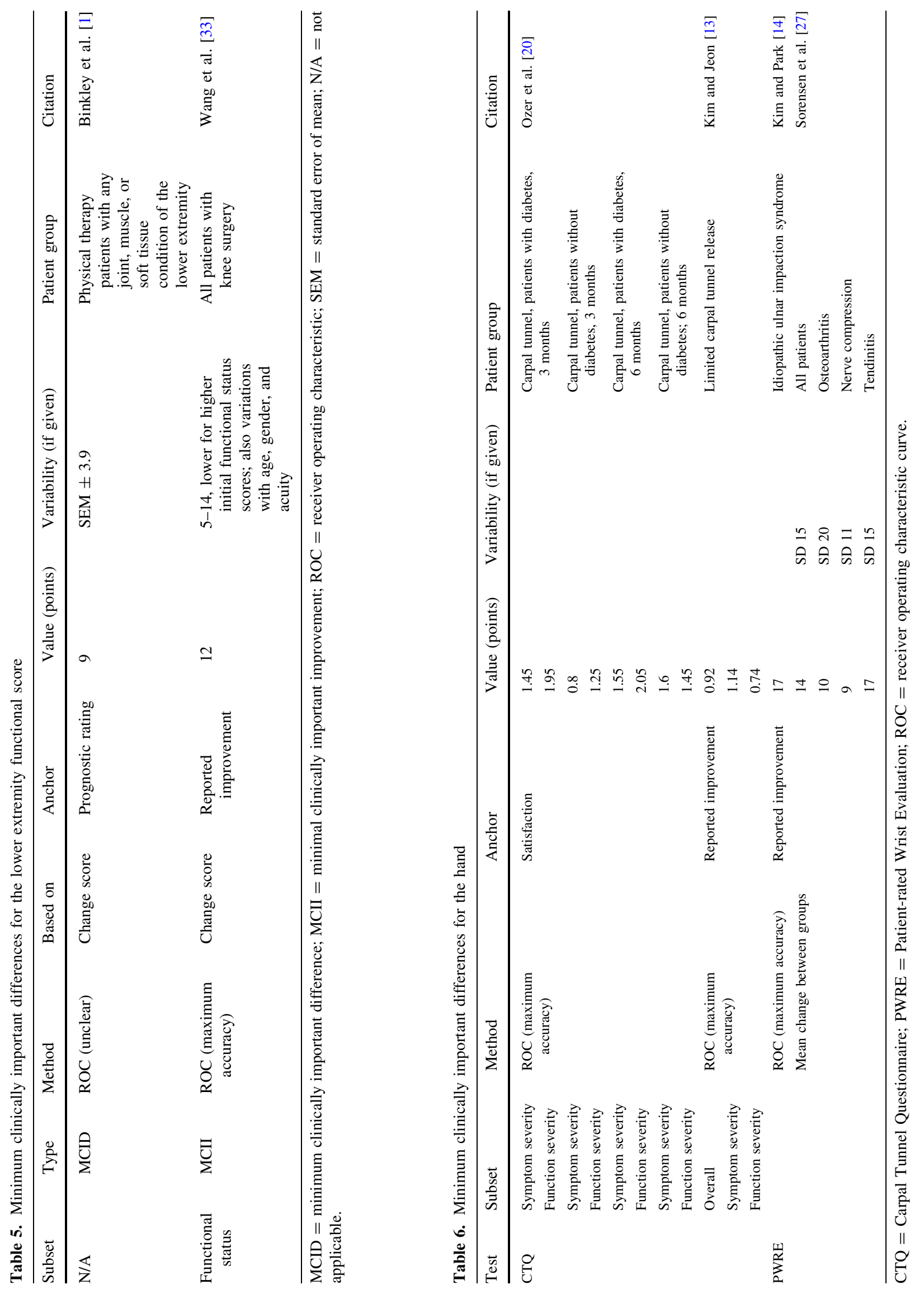




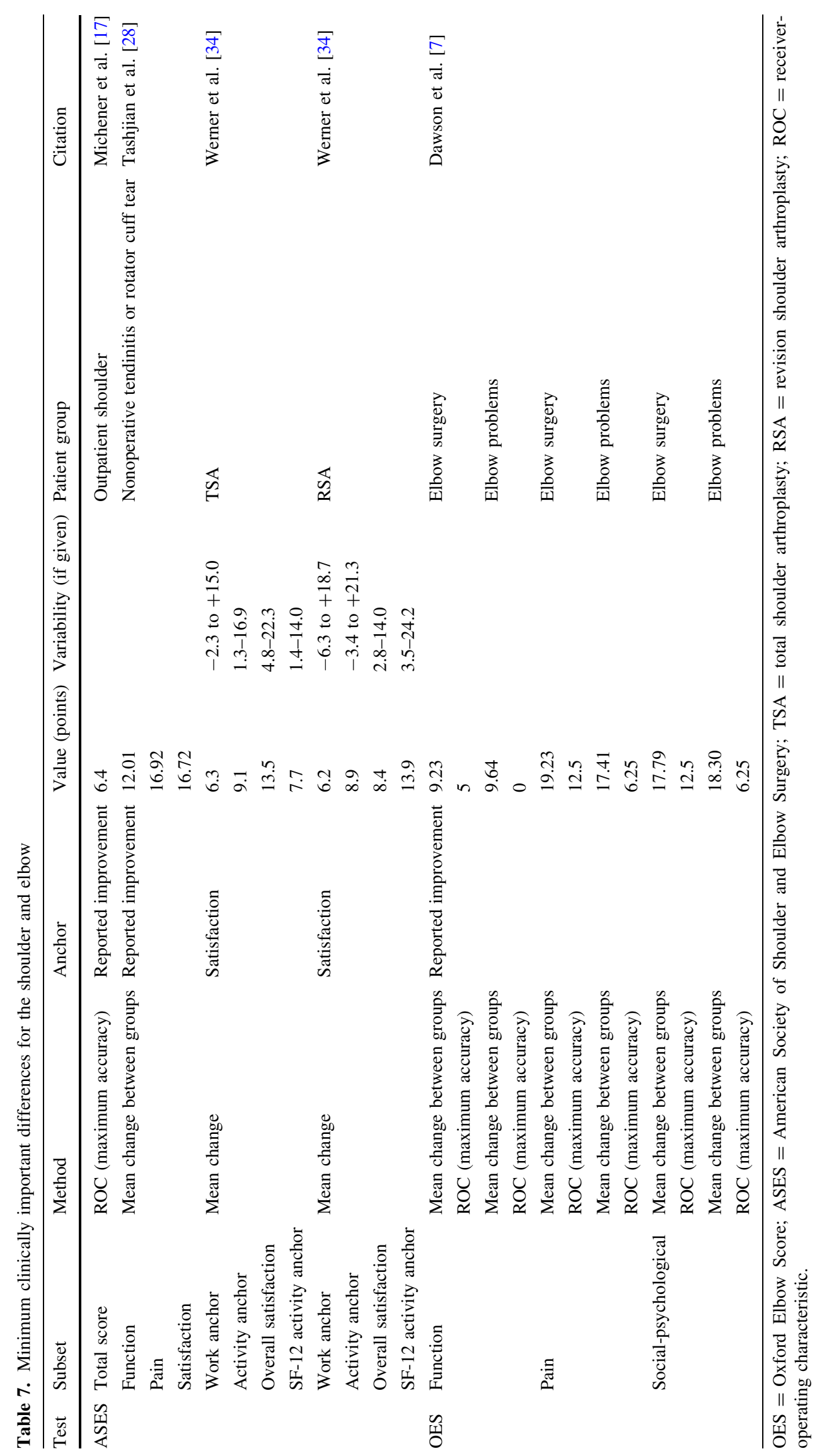




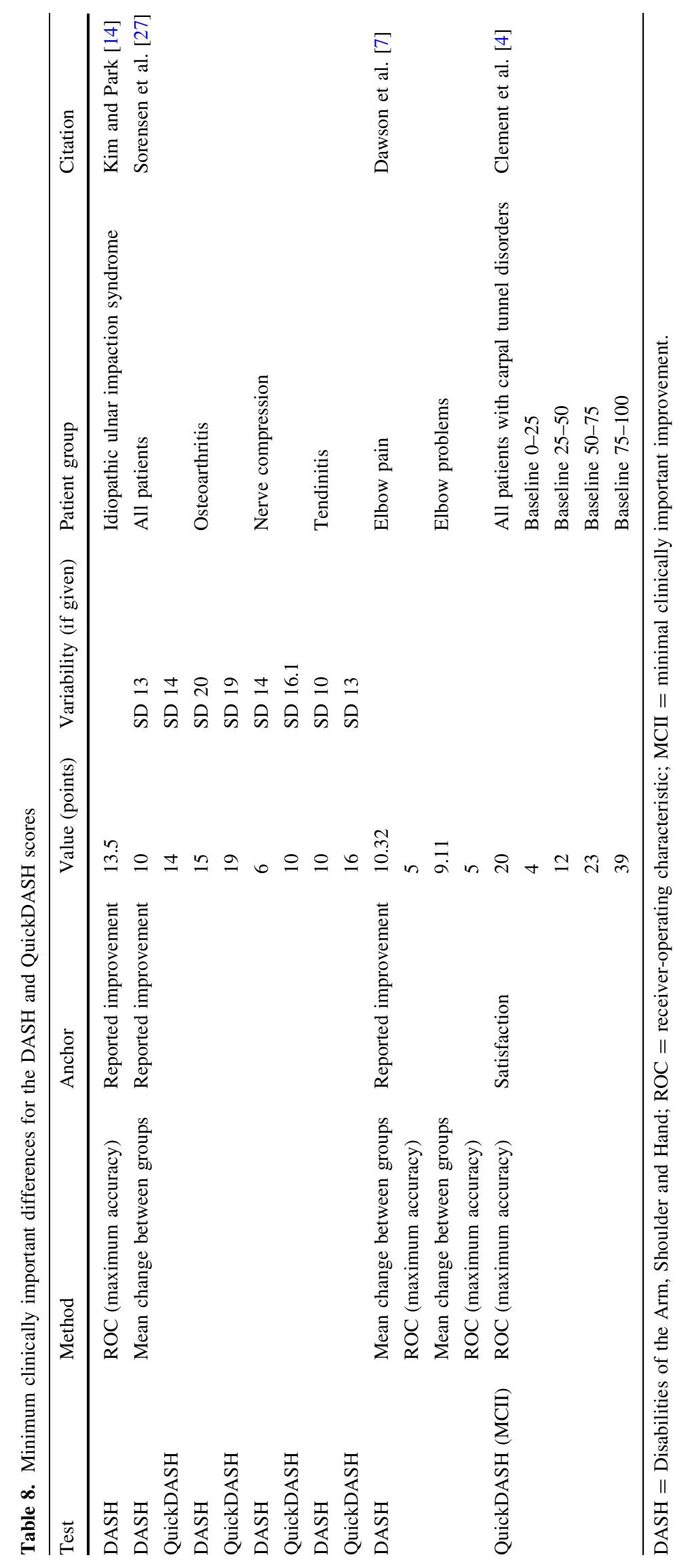


approaches. One approach uses distribution-based methods, based on statistically detectable changes. However, MCIDs calculated using statistical distributions-particularly when they represent small effect sizes-may not reflect clinically important changes. This topic is discussed in more detail in the "Myths and Misconceptions" Section.

The other approach is to define a binary anchor based on a patient's reported outcome-for example, was the patient satisfied, or did (s)he feel that his or her health had improved? In this anchor approach, there are two commonly used methods to estimate MCID. One is to use a statistical test to estimate the difference between patients answering 'yes' and 'no' to the anchor. Another is to use a receiver-operating characteristic (ROC) curve to identify the MCID as the threshold best separating 'yes' and 'no' responses. In studies using the ROC approach, two additional alternatives exist: studies that focus on maximum overall accuracy, and studies that ascertain whether $80 \%$ specificity had been achieved. Importantly, Katz et al. [11] also warn that anchor-based approaches may be misleading in scenarios where a few patients show large benefits, but most show negligible changes.

Although we believe the anchor approach is relatively robust, we acknowledge that different calculation methods lead, unsurprisingly, to different results. Other factors affecting results include whether the calculations were based on raw outcome scores or changes from baseline (MCID vs MCII) and the underlying diagnosis for the patients. Accordingly, we sometimes found a range of possible MCID values for the same outcomes tool (Tables 1-8).

\section{Myths and Misconceptions}

The MCID and the Minimal Detectable Change are the Same (or Even Similar)

They are not the same. By definition, the minimal detectable change (MDC) is the smallest change that can be distinguished from background variation among subjects, which may depend on the variability of the measurement in the population or on the standard error of measurement associated with the test. However, a statistically detectable change may not be one that matters to the patient, although the two may be related. For example, Norman et al. [18] reported that for quality-of-life outcome scores across a range of conditions, the MCID was generally approximately half the standard deviation of the reported scores' ranges, perhaps reflecting discrimination thresholds of patients. If the MDC is less than the MCID/ MCII, then a study may suggest that a treatment results in a difference in outcomes (based on distribution) but the patients may not be able to perceive this difference. If the MCID/MCII is less than the MDC, then we may have the opposite situation, in which numerous patients will report a real benefit, but there is no way to verify it using hard data.

The difference between a statistically detectable and clinically meaningful difference is important (Fig. 1). Imagine a series of clinical studies, each of which returns an estimate of the size of a treatment's effect, with a confidence interval drawn around that estimate. If the confidence interval crosses the vertical line representing "no change," the result is not statistically significant, meaning that the observed "difference" may be simply the influence of chance. If the confidence interval is entirely to the right of the vertical line indicating "no change" then the effect is unlikely to be a chance effect. The clinical importance of this effect increases with its distance from the vertical line; that is, confidence intervals that are to the right of the line of "no change" represent "real" effects, but if they are very close to that line, those treatment effects are very small. Therefore it is possible to have situations that reflect statistically detectable changes, but ones that are not clinically important. It also is possible to have intermediate situations, in which there is no statistical effect but we cannot exclude the possibility of a clinical one (this comes into play when there is insufficient
Fig. 1 A comparison of clinical and statistical significance is presented. The vertical line indicates the "no change" region of a measured effect. The horizontal distance from the line measures strength of the effect. Any confidence interval crossing that vertical line is not statistically significant, and any confidence interval near that line may not be clinically significant.

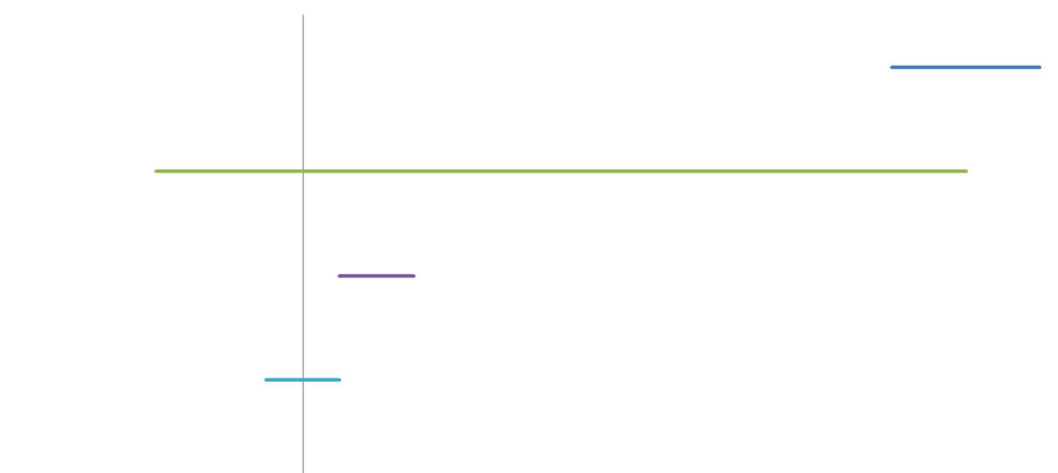

Clinical and statistical

Uncertain clinical or statistical

- Statistical, but definitely not clinical

—Not statistical, definitely not clinical 
statistical power, commonly the result of too few patients studied), or in which there is a statistical effect (the confidence interval remains entirely to the right of the line of "no change"), and the point estimate-such as the mean value on a patient-reported outcomes score, or an odds ratio_-seems large enough to care about, but a confidence interval whose left-hand boundary is a very small number, suggesting the effect may in fact not be clinically important.

For a Specific Outcomes Tool, the MCIDs for Various Treatments of a Single Joint Will Always be the Same (or Even Similar)

One expects MCID estimates to differ depending on patients' pathologic characteristics and comorbidities, even when the same calculation method is used for a given outcomes tool. For example, the MCID for hip osteoarthritis may vary based on whether the operation was a first-time arthroplasty or a revision, and based on the timetable of recovery (Table 1). Other examples include those reported by Ozer et al. [20], who found that patients with diabetes had higher MCIDs on the Carpal Tunnel Questionnaire (Table 6), and Wang et al. [33], who found that the MCID for Lower Extremity Functional Scale scores after treatment are at least in part related to the scores those patients reported at baseline (Table 5) and also that age, gender, and symptom acuity could affect estimated MCIDs.

\section{The MCID Can be Used as a Basis for Planning Studies}

This is not so much a misconception as a potential caveat. Before the current work, a compendium of outcome scores was assembled by Katz et al. [11], who reviewed painful orthopaedic conditions. They found, as we have, that there is a range of MCIDs for the same condition, and that some scores depend on the initial condition of the patient. Their concern was that averaging across groups could be misleading, if only a few patients change substantially, and most patients change only slightly, if at all. They recommended that in clinical trials comparing two treatments, studies should compare the percentages of patients achieving the MCID.

\section{Conclusions}

The tables summarize the range of MCIDs for various outcome tools as an aid to clinicians who may be planning studies or seeking to evaluate patient outcomes in their practices. We caution, based on our findings presented here, that none of the MCID estimates can be considered definitive. However, it may be sufficient for an investigator's purpose to know a range of probable values for differences between patient groups.

\section{Methodologic Note}

The articles referenced were found by using a Boolean search in PubMed using the terms "MCID" or ("Clinically Important" AND ("Minimum" OR "Minimal") plus "orthopedic" in September 2016. These results were not as comprehensive as we had expected, although still broad enough to provide ample evidence of the variation in MCID. We focused on anchor-based methods because they are tied to patient outcomes, whereas statistical detection thresholds (distribution-based methods) may be irrelevant to the patient.

\section{References}

1. Binkley JM, Stratford PW, Lott SA, Riddle DL. The Lower Extremity Functional Scale (LEFS): scale development, measurement properties, and clinical application. North American Orthopaedic Rehabilitation Research Network. Phys Ther. 1999;79:371-383.

2. Bozic KJ. Improving value in healthcare. Clin Orthop Relat Res. 2013;471:368-370.

3. Carragee EJ, Cheng I. Minimum acceptable outcomes after lumbar spinal fusion. Spine J. 2010;10:313-320.

4. Clement ND, Duckworth AD, Jenkins PJ, McEachan JE. Interpretation of the QuickDASH score after open carpal tunnel decompression: threshold values associated with patient satisfaction. J Hand Sur Eur Vol. 2016;41:624-631.

5. Cook CE. Clinimetrics corner: The minimal clinically important change score (MCID): a necessary pretense. J Man Manip Ther. 2008;16:E82-E83.

6. Dawson J, Boller I, Doll H, Lavis G, Sharp R, Cooke P, Jenkinson C. Minimally important change was estimated for the Manchester-Oxford Foot Questionnaire after foot/ankle surgery. $J$ Clin Epidemiol. 2014;67:697-705.

7. Dawson J, Doll H, Boller I, Fitzpatrick R, Little C, Rees J, Carr A. Comparative responsiveness and minimal change for the Oxford Elbow Score following surgery. Qual Life Res. 2008; 17:1257-1267.

8. Dawson J, Doll H, Coffey J, Jenkinson C; Oxford and Birmingham Foot and Ankle Clinical Research Group. Responsiveness and minimally important change for the Manchester-Oxford foot questionnaire (MOXFQ) compared with AOFAS and SF-36 assessments following surgery for hallux valgus. Osteoarthritis Cartilage. 2007;15:918-931.

9. Ebert JR, Smith A, Wood DJ, Ackland TR. A comparison of the responsiveness of 4 commonly used patient-reported outcome instruments at 5 years after matrix-induced autologous chondrocyte implantation. Am J Sports Med. 2013;41:2791-2799.

10. Impellizzeri FM, Mannion AF, Naal FD, Hersche O, Leunig M. The early outcome of surgical treatment for femoroacetabular 
impingement: success depends on how you measure it. Osteoarthritis Cartilage. 2012;20:638-645.

11. Katz NP, Paillard FC, Ekman E. Determining the clinical importance of treatment benefits for interventions for painful orthopedic conditions. J Orthop Surg Res. 2015;10:24.

12. Keurentjes JC, Van Tol FR, Fiocco M, Schoones JW, Nelissen RG. Minimal clinically important differences in health-related quality of life after total hip or knee replacement: a systematic review. Bone Joint Res. 2012;1:71-77.

13. Kim JK, Jeon SH. Minimal clinically important differences in the Carpal Tunnel Questionnaire after carpal tunnel release. J Hand Surg Eur Vol. 2013;38:75-79.

14. Kim JK, Park ES. Comparative responsiveness and minimal clinically important differences for idiopathic ulnar impaction syndrome. Clin Orthop Relat Res. 2013;471:1406-1411.

15. Kvien TK, Heiberg T, Hagen KB. Minimal clinically important improvement/difference (MCII/MCID) and patient acceptable symptom state (PASS): what do these concepts mean? Ann Rheum Dis. 2007;66(suppl 3):iii40-iii41.

16. Lieberman JR. American Association of Hip and Knee Surgeons and outcome measures after total joint arthroplasty. J Arthroplasty. 2016;31:1137-1138.

17. Michener LA, McClure PW, Sennett BJ. American Shoulder and Elbow Surgeons Standardized Shoulder Assessment Form, patient self-report section: reliability, validity, and responsiveness. J Shoulder Elbow Surg. 2002;11:587-594.

18. Norman GR, Sloan JA, Wyrwich KW. Interpretation of changes in health-related quality of life: the remarkable universality of half a standard deviation. Med Care. 2003;41:582-592.

19. Nwachukwu BU, Hamid KS, Bozic KJ. Measuring value in orthopaedic surgery. JBJS Rev. 2013;1. pii: 01874474201311000-00003. doi: 10.2106/JBJS.RVW.M.00067.

20. Ozer K, Malay S, Toker S, Chung KC. Minimal clinically important difference of carpal tunnel release in diabetic and nondiabetic patients. Plast Reconstr Surg. 2013;131:1279-1285.

21. Parker SL, Mendenhall SK, Shau DN, Adogwa O, Anderson WN, Devin CJ, McGirt MJ. Minimum clinically important difference in pain, disability, and quality of life after neural decompression and fusion for same-level recurrent lumbar stenosis: understanding clinical versus statistical significance. J Neurosurg Spine. 2012;16:471-478.

22. Paulsen A, Roos EM, Pedersen AB, Overgaard S. Minimal clinically important improvement (MCII) and patient-acceptable symptom state (PASS) in total hip arthroplasty (THA) patients 1 year postoperatively. Acta Orthop. 2014;85:39-48.

23. Singh JA, Luo R, Landon GC, Suarez-Almazor M. Reliability and clinically important improvement thresholds for osteoarthritis pain and function scales: a multicenter study. J Rheumatol. 2014;41:509-515.

24. Singh JA, Schleck C, Harmsen S, Lewallen D. Clinically important improvement thresholds for Harris Hip Score and its ability to predict revision risk after primary total hip arthroplasty. BMC Musculoskelet Disord. 2016;17:256.
25. Singh JA, Schleck C, Harmsen WS, Lewallen DG. Validation of the Mayo Hip Score: construct validity, reliability and responsiveness to change. BMC Musculoskelet Disord. 2016;17:39.

26. Skolasky RL, Albert TJ, Maggard AM, Riley LH 3rd. Minimum clinically important differences in the Cervical Spine Outcomes Questionnaire: results from a national multicenter study of patients treated with anterior cervical decompression and arthrodesis. J Bone Joint Surg. Am. 2011;93:1294-1300.

27. Sorensen AA, Howard D, Tan WH, Ketchersid J, Calfee RP. Minimal clinically important differences of 3 patient-rated outcomes instruments. J Hand Surg Am. 2013;38:641-649.

28. Tashjian RZ, Deloach J, Green A, Porucznik CA, Powell AP. Minimal clinically important differences in ASES and simple shoulder test scores after nonoperative treatment of rotator cuff disease. J Bone Joint Surg Am. 2010;92:296-303.

29. Tetreault L, Nouri A, Kopjar B, Côté P, Fehlings MG. The minimum clinically important difference of the Modified Japanese Orthopaedic Association Scale in patients with degenerative cervical myelopathy. Spine (Phila Pa 1976). 2015;40:1653-1659.

30. Tonosu J, Takeshita K, Hara N, Matsudaira K, Kato S, Masuda K, Chikuda $\mathrm{H}$. The normative score and the cut-off value of the Oswestry Disability Index (ODI). Eur Spine J. 2012;21:15961602.

31. Tubach F, Ravaud P, Beaton D, Boers M, Bombardier C, Felson DT, van der Heijde D, Wells G, Dougados M. Minimal clinically important improvement and patient acceptable symptom state for subjective outcome measures in rheumatic disorders. J Rheumatol. 2007;34:1188-1193.

32. Tugwell P, Boers M, Brooks P, Simon L. Strand V, Idzerda L. OMERACT: An international initiative to improve outcome measurement in rheumatology. Trials. 2007; 8: 38. doi:10.1186/ 1745-6215-8-38. Available at: http://www.ncbi.nlm.nih.gov/pmc/ articles/PMC2169260/. Accessed September 7, 2016.

33. Wang YC, Hart DL, Stratford PW, Mioduski JE. Baseline dependency of minimal clinically important improvement. Phys Ther. 2011;91:675-688.

34. Werner BC, Chang B, Nguyen JT, Dines DM, Gulotta LV. What change in American Shoulder and Elbow Surgeons Score represents a clinically important change after shoulder arthroplasty? Clin Orthop Relat Res. 2016;474:2672-2681.

35. Wright A, Hannon J, Hegedus EJ, Kavchak AE. Clinimetrics corner: a closer look at the minimal clinically important difference (MCID). J Man Manip Ther. 2012;20:160-166.

36. Zhou F, Zhang Y, Sun Y, Zhang F, Pan S, Liu Z. Assessment of the minimum clinically important difference in neurological function and quality of life after surgery in cervical spondylotic myelopathy patients: a prospective cohort study. Eur Spine J. 2015;24:2918-2923.

37. Zuckerman SL, Chotai S, Devin CJ, Parker SL, Stonko DP, Wick JB, Hale AT, McGirt MJ, Cheng JS. Surgical resection of intradural extramedullary spinal tumors: patient reported outcomes and minimum clinically important difference. Spine (Phila Pa 1976). 2016 Apr 20. [Epub ahead of print] 